\title{
PENENTUAN DAERAH IMBUHAN DENGAN METODE ANALISIS ISOTOP AIR TANAH DI DESA CURAH COTTOK, KEC. KAPONGAN KABUPATEN SITUBONDO
}

\author{
M. Haris Miftakhul Fajar, Widya Utama, Mariyanto, Firman Syaifuddin Akbar, Anik Hilyah, Juan Pandu \\ Gya Nur Rochman, M. Singgih Purwanto \\ Departemen Teknik Geofisika, Fakultas Teknik Sipil Lingkungan dan Kebumian, \\ Institut Tenologi Sepuluh Nopember (ITS) \\ e-mail : mharismf@geofisika.its.ac.id
}

\begin{abstract}
Abstrak. Lokasi penelitian di Desa Curah Cottok Kec. Kepongan Kabupaten Sitobondo, memiliki karakteristik morfologi yang unik, yaitu perbukitan memanjang arah barat-timur (elevasi 25-500 mdpl) dengan dibatasi oleh dataran rendah di sebelah utara (elevasi 0-25 mdpl) dan selatannya (elevasi 50-200 mdpl). Berdasarkan pengamatan lapangan, dataran rendah di sebelah utara perbukitan memiliki beberapa mata air dan sumur artesis dengan debit 1-7 liter/detik. Dengan topografi yang unik tersebut, terdapat 3 zona yang memungkinkan berperan sebagai daerah imbuhan dari mata air dan sumur artesis, yaitu zona 1 berupa daerah Perbukitan Curah Cottok, zona 2 berupa dataran di sebelah selatan Perbukitan Curah Cottok dan zona 3 berupa lereng utara Gunung ljen. Tujuan dari penelitan ini adalah menentukan lokasi daerah imbuhan dari air tanah yang keluar melalui mata air dan sumur artesis. Untuk memastikan lokasi daerah imbuhan, dilakukan dengan menggunakan analisis isotop, yaitu dengan isotop ${ }^{2} \mathrm{H}$ dan ${ }^{18} \mathrm{O}$. Selain penentuan lokasi daerah imbuhan, analisis isotop air tanah juga dapat digunakan untuk melakukan analisis umur air (water dating), yaitu dengan menggunakan analisis isotop ${ }^{3} \mathrm{H}$. Berdasarkan data isotop ${ }^{2} \mathrm{H}$ dan ${ }^{18} \mathrm{O}$ daerah imbuhan dari air tanah yang keluar melalui mata air dan sumur artesis di lokasi penelitian berada pada ketinggian 550-1.200 mdpl. Berdasarkan analisis isotop ${ }^{3} \mathrm{H}$, waktu yang diperlukan air tanah untuk mengalir melalui akuifer mulai dari daerah imbuhan sampai di Desa Curah Cottok membutuhkan waktu sekitar 22 tahun.

Kata Kunci: air tanah; isotop; daerah imbuhan; water dating
\end{abstract}

\begin{abstract}
Research location in the Curah Cottok Village, District Kepongan, Sitobondo Regency, has unique morphological characteristics, namely hills extending west-east (elevation 25-500 masl) with boundaries by the lowlands on the north (0-25 masl) and south (elevations 50-200 masl). Based on field observations, the lowlands in the northern hills have several springs and artesian wells with a flow of 1-7 liters/second. With this unique topography, there are three possible zones which act as recharge areas of springs and artesian wells, namely first zone is Curah Cottok Hills region, second zone is plain in the south of the Curah Cottok Hills and third zone is the northern slope of Mount ljen. The purpose of this research is to determine the location of the recharge area from the ground water coming out through the springs and artesian wells. To ascertain the location of the recharge area, it is carried out using isotope analysis, namely with ${ }^{2} \mathrm{H}$ and ${ }^{18} \mathrm{O}$ isotopes. In addition to determining the location of the recharge area, analysis of groundwater isotopes can also be used to conduct water dating analysis, namely by using ${ }^{3} \mathrm{H}$ isotope analysis. Based on ${ }^{2} \mathrm{H}$ and ${ }^{18} \mathrm{O}$ isotope data, the infiltration area from groundwater that came out through the springs and artesian wells at the study site was at an altitude of 550-1.200 masl. Based on ${ }^{3} \mathrm{H}$ isotope analysis, the time needed for groundwater to flow through aquifers starting from the recharge area to the Curah Cottok Village takes about 22 years.
\end{abstract}

Keywords: groundwater; isotope; recharge area; water dating

\section{PENDAHULUAN}

Lokasi penelitian berada di Desa Curah Cottok, Kec. Kapongan, Kab. Situbondo. Di lokasi penelitian, terdapat kenampakan morfologi yang cukup menarik berupa perbukitan. Dalam penelitian ini, perbukitan ini disebut sebagai perbukitan Curah
Cottok dengan ketinggian 25-500 mdpl (Gambar 1). Perbukitan ini dibatasi oleh dataran baik di sebelah utara maupun selatan. Dataran di sebelah selatan memiliki ketinggian 50-200 mdpl, sedangkan dataran di sebelah utara memiliki ketinggian 0-25 mdpl. 


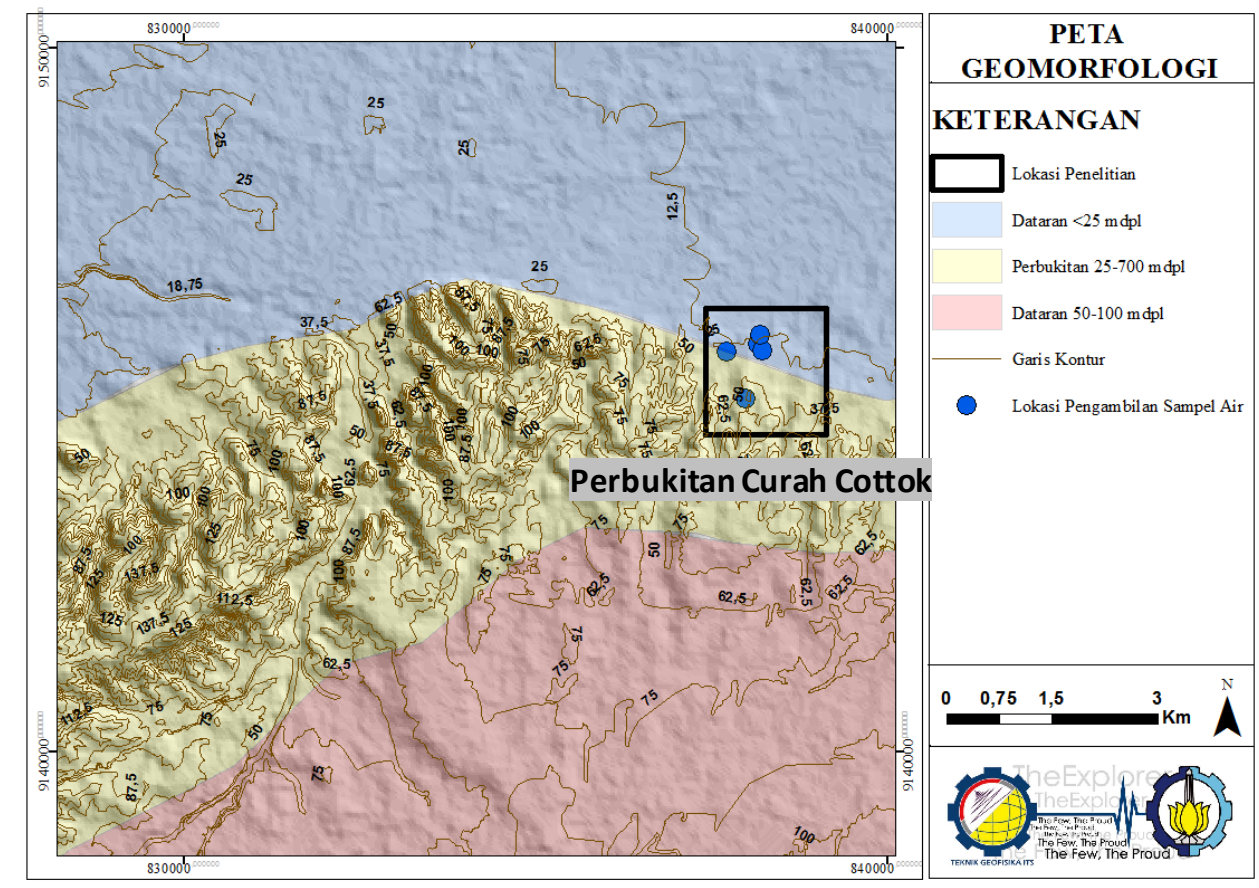

Gambar 1 Peta Geomorfologi di lokasi penelitian. Terlihat pada peta di sekitar lokasi penelitian terdapat 3 morfologi, yaitu morfologi perbukitan dengan elevasi $50-500 \mathrm{mdpl}$, morfologi dataran dengan elevasi $<25 \mathrm{mdpl}$ dan 50-100mdpl.

Perbedaan morfologi ini, memiliki keselarasan hubungan dengan kesuburan tanah serta ketersediaan sumber air bersih. Pada daerah perbukitan, sebagian besar lahannya berupa lahan kosong dan setempat perkebunan. Hal ini dikarenakan kurangnya sumber air di daerah perbukitan. Sedangkan di daerah dataran merupakan daerah dengan suplai air bersih yang cukup sehingga lahannya dapat dimanfaatkan sebagai area persawahan dan pemukiman. Pada daerah dataran yang berada di sebelah utara Perbukitan Curah Cottok, ditemukan beberapa mata air dan sumur bor artesis yang menjadi salah satu suplai air bersih di lokasi tersebut. Berdasarkan survei lapangan, debit mata air dan sumur artesis antara 1-7 liter/detik.

Kemunculan mata air di lokasi ini sangat menarik perhatian. Hal ini karena $700 \mathrm{~m}$ dari kemunculan mata air ke arah selatan merupakan perbukitan tandus dan gersang. Di sisi lain kondisi daerah dari lokasi mata air ke arah utara merupakan daerah subur dengan berlimpahnya sumber air. Penelitian ini bertujuan untuk menentukan hubungan antara air tanah dengan morfologi di daerah tersebut. Hubungan yang dimaksud dalam penelitian ini adalah menentukan lokasi daerah imbuhan dari mata air yang muncul di sebelah utara Perbukitan Curah Cottok.

Penentuan lokasi daerah imbuhan berdasarkan pengamatan topografi (Danaryanto dkk., 2008), terdapat 3 kandidat zona daerah imbuhan yaitu zona 1 berupa Perbukitan Curah Cottok, zona 2 berupa dataran di sebelah selatan Perbukitan Curah Cottok dan zona 3 berupa lereng utara Gunung Ijen (Gambar 2). Ketiga lokasi ini dapat menjadi kandidat daerah imbuhan dari air tanah di Desa Curah Cottok karena lokasinya yang lebih tinggi dari pada daerah kemunculan mata air dan sumur artesis di lokasi penelitian. Selain itu, keterdapatan dataran di sebelah selatan perbukitan Curah Cottok, yang membentuk konfigurasi cekungan dengan dibatasi oleh Gunung ljen di sebelah selatan dan Perbukitan Curah Cottok di sebelah utara, dapat menjadi salah satu sebab utama terkumpulnya air permukaan kemudian terinfiltrasi dan menyuplai air tanah di lokasi penelitian. Selanjutnya untuk mendetailkan lokasi daerah imbuhan yang diperoleh melalui pengamatan topografi, dilakukan dengan menggunaakan analisis isotop deuterium ${ }^{2} \mathrm{H}$ dan ${ }^{18} \mathrm{O}$. 


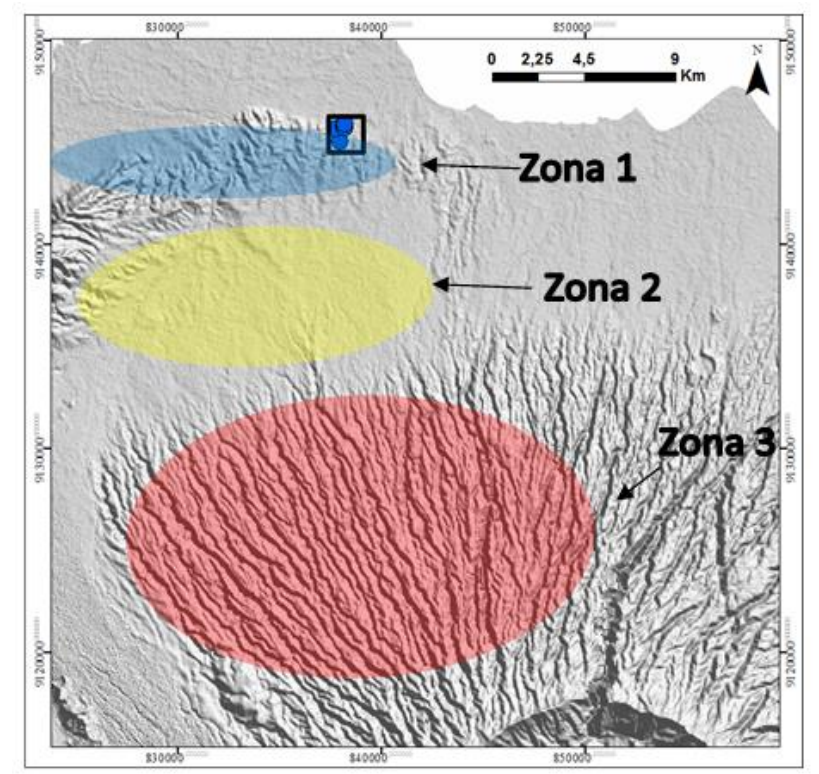

Gambar 2 Berdasarkan pengamatan morfologi, tedapat 3 zona yang dapat menjadi daerah imbuhan, yaitu zona 1 (Perbukitan Curah Cottok), zona 2 (dataran di sebelah selatan Perbukitan Curah Cottok) dan zona 3 (lereng utara Gunung Ijen). Simbol kotak adalah lokasi pengambilan sampel air bersimbol lingkaran biru

Setelah lokasi daerah imbuhan dapat ditentukan, dilanjutkan dengan melakukan analisis umur air tanah. Analisis ini bertujuan untuk dapat mengetahui waktu yang diperlukan oleh air tanah untuk mengalir melalui akuifer dari infiltrasi air hujan sampai keluar sebagai mata air maupun melalui sumur artesis. Analisis umur air tanah pada penelitian ini menggunakan metode analisis tritium $\left({ }^{3} \mathrm{H}\right)$, karena diperkirakan umur air tanah kurang dari 50 tahun (Mazor, 1997).

\section{METODOLOGI}

Untuk mengetahui lokasi daerah imbuhan di lokasi penelitian, dilakukan dengan menggunakan analisis isotop ${ }^{2} \mathrm{H}$ dan ${ }^{18} \mathrm{O}$. Prinsip dari metode ini adalah, kandungan isotop ${ }^{2} \mathrm{H}$ dan ${ }^{18} \mathrm{O}$ di dalam awan, akan berkurang seiring dengan jarak perjalanan awan mulai dari awal penguapan, yang pada umumnya berada di laut. Isotop berat pada $\mathrm{H}$ dan $\mathrm{O}$ dalam $\mathrm{H}_{2} \mathrm{O}$ akan terpresipitasi lebih dahulu.

Oleh karena itu, dalam analisis ini memerlukan data kandungan isotop air hujan pada elevasi tertentu. Dalam penelitian ini, data isotop air hujan atau biasa disebut sebagai LMWL (local meteoric water line) tidak tersedia di lokasi penelitian sehingga menggunakan LMWL dari lokasi lain, yaitu LMWL dari Gunung Tengger berdasarkan penelitian Hendrayana dkk. (2015). Untuk memperoleh ketinggian daerah imbuhan, data kandungan isotop dari sampel air tanah dimasukkan ke dalam grafik LMWL.

Analisis kedua adalah analisis umur air tanah menggunaan data isotop tritium $\left({ }^{3} \mathrm{H}\right)$. Metode ini disajikan dalam rumus (Mazor, 1997):

$$
t=-17,93 * \ln (A t / A 0)
$$

dengan

$\mathrm{t} \quad$ : umur air tanah

At : jumlah konsentrasi tritium dalam sampel

A0 : jumlah konstrasi tritium mula-mula

Menurut Santi (2013) kandungan tritium $\left({ }^{3} \mathrm{H}\right) \mathrm{di}$

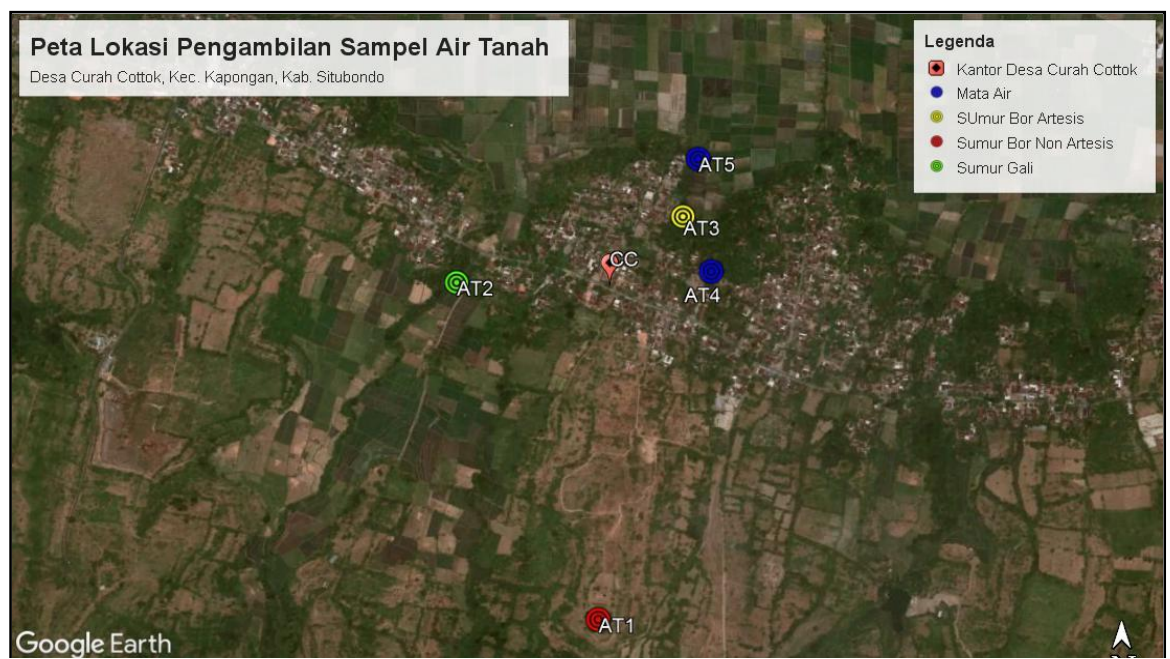

Gambar 3 Peta lokasi pengambilan sampel air tanah di Desa Curah Cottok Kec. Kapongan Kab. Situbondo 
udara yang berada di Indonesia pada umumnya berjumlah 9.

Dalam penelitian ini pengambilan sampel air tanah dilakukan di lima (5) lokasi untuk dilakukan analisis isotop. Setiap sampel air tanah yang telah diambil, dibawa ke laboratorium BATAN untuk dilakukan uji kandungan isotop ${ }^{18} \mathrm{O},{ }^{2} \mathrm{H}$ dan ${ }^{3} \mathrm{H}$. Analisis uji isotop ${ }^{18} \mathrm{O}$ dan ${ }^{2} \mathrm{H}$ digunakan untuk melakukan analisis daerah imbuhan, sedangkan uji isotop ${ }^{3} \mathrm{H}$ (tritium) digunakan untuk analisis umur air tanah. Lokasi pengambilan sampel ditunjukkan pada Gambar 3.

\section{HASIL DAN PEMBAHASAN}

Data hasil uji laboratorium isotop ${ }^{18} \mathrm{O},{ }^{2} \mathrm{H}$ dan ${ }^{3} \mathrm{H}$ dari BATAN ditunjukkan pada Tabel 1 . Dari data kandungan isotop ${ }^{18} \mathrm{O},{ }^{2} \mathrm{H}$, kemudian dilakukan overlay dengan LMWL (local meteoric water line) Gunung Tengger. Hasil dari hasil overlay tersebut ditunjukkan pada Gambar 4 dan Gambar 5.

Tabel 1. Kandungan isotop ${ }^{18} \mathrm{O},{ }^{2} \mathrm{H}$ dan tritium dari sampel air tanah di lokasi penelitian

\begin{tabular}{c|cccc}
\hline No & Kode Sampel & $\begin{array}{c}\delta^{18} O \\
\text { (0/00)SMOW }\end{array}$ & $\begin{array}{c}\delta D \\
\text { (0/00)SMOW }\end{array}$ & $\begin{array}{c}\text { Triti } \\
\text { um }\end{array}$ \\
\hline 1 & AT1 & $-5,98$ & $-35,3$ & - \\
2 & AT2 & $-5,26$ & $-32,8$ & - \\
3 & AT3 & $-6,79$ & $-39,6$ & 2,56 \\
4 & AT4 & $-7,13$ & $-41,6$ & - \\
5 & AT5 & $-7,34$ & $-44,2$ & 2,79 \\
\hline
\end{tabular}

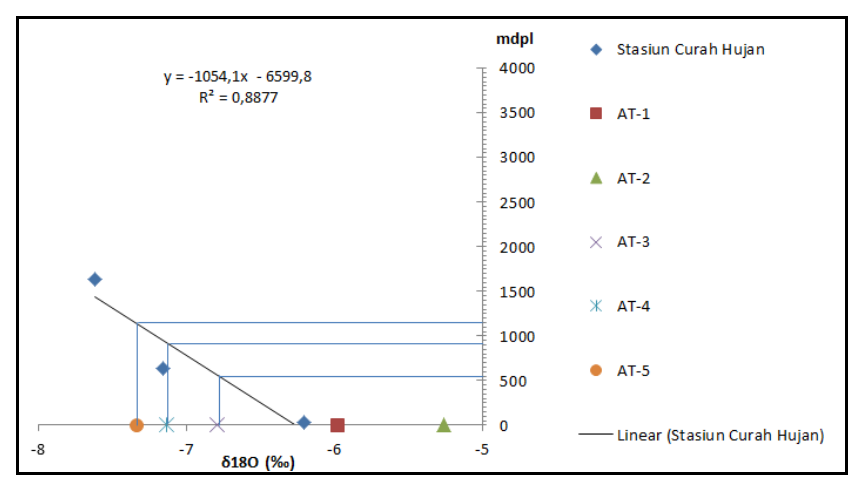

Gambar 4 Overlay data isotop 180 dengan LMWL. Dari grafik memperlihatkan bahwa AT5, AT4 dan AT 3 memiliki kandungan isotop yang identik dengan air hujan pada ketinggian 1168, 915 dan 557 mdpl
Berdasarkan analisis isotop ${ }^{18} \mathrm{O}$, menunjukkan bahwa sampel dari lokasi AT3, AT4 dan AT5 memiliki kandungan isotop yang mencerminkan air hujan dari ketinggian berturut- turut 557, 915 dan 1.168 mdpl. Menurut analisis isotop ${ }^{2} \mathrm{H}$ menujukkan hasil yang tidak jauh berbeda, yaitu 549, 816 dan 1.188 mdpl. Oleh karena itu, berdasarkan analisis isotop ${ }^{18} \mathrm{O}$ dan ${ }^{2} \mathrm{H}$ air tanah dari AT3, AT4 dan AT 5 memiliki daerah imbuhan pada ketinggian 550-1.200 mdpl.

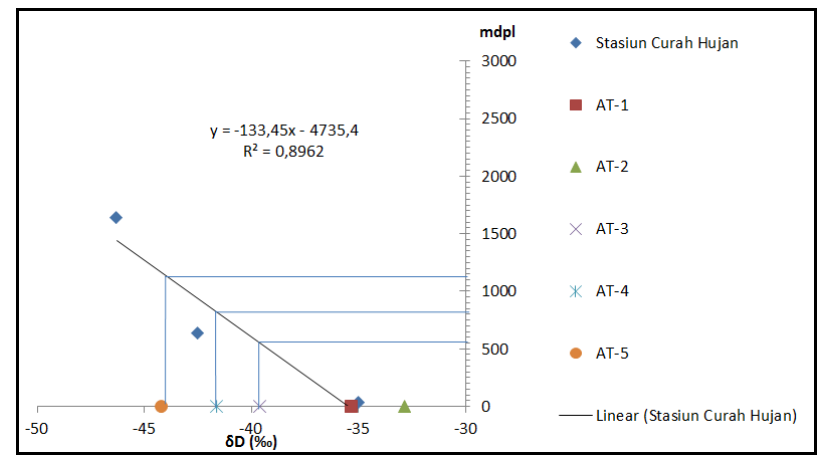

Gambar 5 Overlay data isotop $2 \mathrm{H}$ (deuterium) dengan LMWL. Dari grafik memperlihatkan bahwa AT5, AT4 dan AT 3 memiliki kandungan isotop yang identik dengan air hujan pada ketinggian 1188, 816 dan 549 mdpl

Analisis daerah imbuhan pada sumur AT1 dan AT2 menunjukkan hasil yang berbeda bila dibanding AT3, AT4 dan AT5. Analisis zona imbuhan dari sampel air tanah AT1 dan AT2, yaitu menunjukkan daerah imbuhan berada pada ketinggian di bawah 0 mdpl. Hal ini bisa dikarenakan 2 hal, yaitu karena adanya kesalahan prosedur pengambilan sampel air tanah, atau adanya sistem akuifer yang berbeda antara AT 1 dan AT 2 dengan AT 3, AT 4 dan AT 5.

Oleh karena daerah imbuhan berdasarkan analisis isotop menunjukkan pada daerah berketinggian 550-1.200 mdpl, maka langkah selanjutnya adalah meng-overlay-kan data tersebut dengan peta topografi. Dari hasil overlay terlihat bahwa lokasi berketinggian 550-1.200 mdpl berada di sisi utara lereng Gunung ljen Gambar 6.

Analisis imbuhan berdasarkan analisis isotop, hanya dapat menentukan batas atas dan bawah (elevasi). Untuk mengetahui batas kanan dan kiri, diperlukan penelitian hidrogeologi yang lebih detail dan komprehensif. 


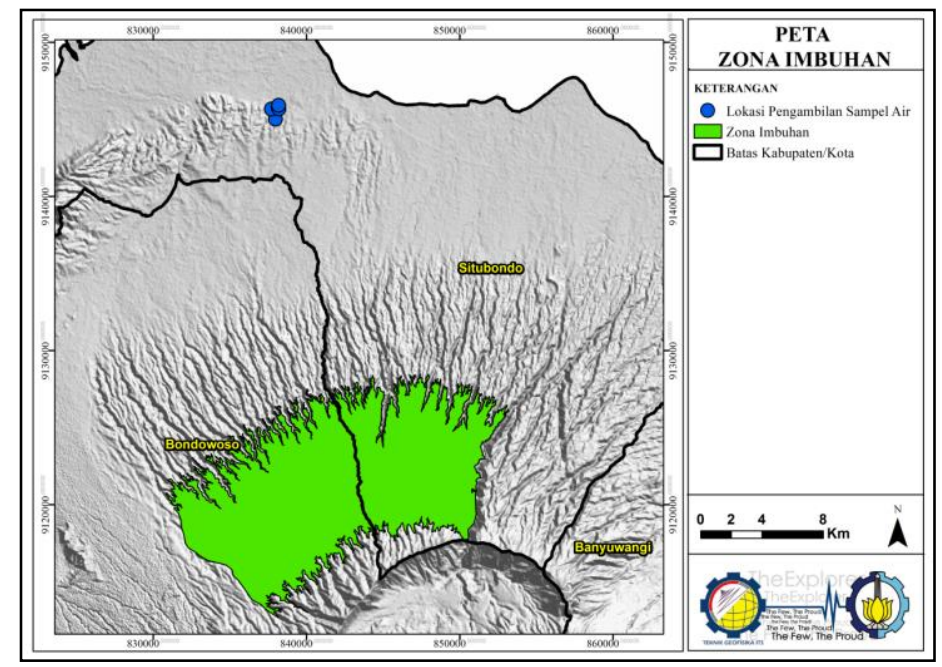

Gambar 6 Peta zona imbuhan air tanah di Desa Curah Cottok Kab. Situbondo. Zona imbuhan dibatasi oleh elevasi 550-1200 mdpl. Untuk batas kanan dan kiri zona imbuhan perlu dilakukan penelitian lebih lanjut.

Berdasarkan data isotop $T$ yang telah dianalisis di Laboratorium BATAN, dilakukan analisis dengan mengasumsikan bahwa kondisi awal $\mathrm{T}$ di udara Indonesia berjumlah 9 (Santi, 2013). Hasil analisis T ditunjukkan pada Tabel 2. Kandungan T pada setiap sampel kemudian dimasukkan kedalam persamaan (1) untuk mengetahui umur air tanah. Dari analisis ini diketahui bahwa umur air tanah yang keluar dari mata air di Desa Curah Cottok (AT3 dan AT5) berasal dari hujan 20,9 dan 22,5 tahun yang lalu.

Tabel 2. Data isotop tritium serta umur air tanah di lokasi penelitian

\begin{tabular}{|c|c|c|c|}
\hline No & Kode Sampel & $\mathrm{T}(\mathrm{TU})$ & Umur \\
\hline 1 & AT3 & 2,56 & 22,5 \\
\hline 2 & AT5 & 2,79 & 20,9 \\
\hline
\end{tabular}

\section{PENUTUP}

\section{Simpulan dan Saran}

Berdasarkan survei hidrogeologi dan analisis isotop air tanah, dapat diketahui bahwa sistem air tanah di Desa Curah Cottok dimulai dari daerah imbuhan pada ketinggian 550-1.200 mdpl. Pada daerah dengan ketinggian ini air hujan yang jatuh, sebagian mengalami infiltrasi dan membentuk sistem air tanah. Air tanah ini mengalir melalui akuifer sepanjang hampir $20 \mathrm{~km}$ sampai di Desa Curah Cottok. Waktu yang diperlukan air tanah untuk mengalir melalui akuifer mulai dari daerah imbuhan sampai di Desa Curah Cottok membutuhkan waktu sekitar 22 tahun.

Berdasarkan data isotop, diketahui bahwa air tanah yang diambil dari AT1 dan AT2, menunjukkan lokasi daerah imbuhan berada pada elevasi dibawah $0 \mathrm{mdpl}$. Hal ini bisa dikarenakan 2 hal, yaitu karena adanya kesalahan prosedur pengambilan sampel air tanah, atau adanya sistem akuifer yang berbeda antara AT 1 dan AT 2 dengan AT 3, AT 4 dan AT 5. Oleh karena itu perlu dilakukan analisis hidrogeologi lebih detail untuk bisa mengetahui hidrostratigrafi, fasies air tanah serta sistem akuifer di lokasi penelitian. Selain itu analisis imbuhan berdasarkan analisis isotop, hanya dapat menentukan batas atas dan bawah (elevasi). Untuk mengetahui batas kanan dan kiri, diperlukan penelitian hidrogeologi yang lebih detail dan komprehensif.

\section{Ucapan Terima Kasih}

Penulis menyampaikan terimakasih kepada Departemen Teknik Geofisika ITS Surabaya karena penelitian ini dapat terlaksana atas hibah penelitian Departemen Teknik Geofisika ITS tahun 2018.

\section{DAFTAR PUSTAKA}

Danaryanto, Robert J. Kodoatie, Satriyo Hadipurwo dan Sri Sangkawati (2008), Manajemen Air Tanah 
Berbasis Cekungan Air Tanah, Kementerian Energi dan Sumber Daya Mineral.

David Keith Todd dan Larry W. Mays (2005), Groundwater Hydrogeology, 3 Ed., John Wiley and Sons, New York.

Heru Hendrayana, H.H., M. Haris Miftakhul Fajar, M.H.M.F. dan Wahyu Wilopo, W.W. (2015), "SISTEM AIR TANAH ENDAPAN VULKANIK LERENG GUNUNG BROMO KABUPATEN PROBOLINGGO PROVINSI JAWA TIMUR", PROCEEDING, SEMINAR NASIONAL KEBUMIAN KE-8 Academia-Industry Linkage 15-16 OKTOBER 2015; GRHA SABHA PRAMANA, Diambil dari https://repository.ugm.ac.id/135522/.

Mazor, E. (1997), Chemical and Isotopic Groundwater Hydrology: The Applied Approach, 2nd ed., rev. and expanded., M. Dekker, New York :

Santi, N. (2013), Karakteristik Hidrogeokimia Mataair di Lereng Gunung Merapi Bagian Timur, Kabupaten Boyolali dan Klaten, Provinsi Jawa Tengah., Universitas Gadjah Mada. Diambil dari http://etd.repository.ugm.ac.id/index.php?mod=pen elitian_detail\&sub=PenelitianDetail\&act=view\&typ=h tml\&buku_id=63444. 